\title{
MALE-BIASED DISPERSAL IN A FEMALE-DISPERSED SYMBIOSIS
}

\author{
Alix Matthews ${ }^{1}$, Katrin Kellner ${ }^{2}$, and Jon Seal ${ }^{2}$ \\ ${ }^{1}$ Arkansas State University \\ ${ }^{2}$ University of Texas at Tyler
}

October 19, 2020

\begin{abstract}
For nearly all organisms, dispersal is a fundamental life history trait that can shape their ecology and evolution. Variation in dispersal capabilities within a species exists and can influence population genetic structure and ecological interactions. In fungus-gardening (attine) ants, co-dispersal of ants and mutualistic fungi is crucial to the success of this obligate symbiosis. Female-biased dispersal (and gene flow) may be favored in attines because virgin queens carry the responsibility of dispersing the fungi, but a paucity of research has made this conclusion difficult. Here, we investigate dispersal of the fungus-gardening ant Trachymyrmex septentrionalis using a combination of maternally- (mitochondrial DNA) and biparentally-inherited (microsatellites) markers. We found three distinct, spatially isolated mitochondrial DNA haplotypes. Two were found in the Florida panhandle and the other was found in the Florida peninsula. In contrast, biparental markers illustrated significant gene flow across this region and minimal spatial structure. The differential patterns uncovered from mitochondrial DNA and microsatellite markers suggest that most long-distance ant dispersal is male-biased and that females (and concomitantly the fungus) have more limited dispersal capabilities. Consequently, the limited female dispersal is likely an important bottleneck for the fungal symbiont. This bottleneck could slow fungal genetic diversification, which has significant implications for both ant hosts and fungal symbionts regarding population genetics, species distributions, adaptive responses to environmental change, and coevolutionary patterns.
\end{abstract}

\section{INTRODUCTION}

Dispersal is a ubiquitous and fundamental life history trait that plays a role in the evolutionary ecology of organisms. Dispersal can shape population genetic differentiation, overall species distributions, and how species may respond or adapt to environmental change (Clobert, Baguette, Benton, \& Bullock, 2012; Ellis et al., 2015). For species with low dispersal capabilities, historical, ecological, or anthropogenic barriers to movement can influence their population genetic structure over certain scales (Doña et al., 2019; Haye et al., 2014; Manel, Schwartz, Luikart, \& Taberlet, 2003; Storfer, Murphy, Spear, Holderegger, \& Waits, 2010). For example, barriers may slow gene flow between some populations, increase reproductive and genetic isolation, and ultimately result in genetically divergent populations (Clark, Brown, Stechert, \& Zamudio, 2010; DiBlasi et al., 2018; Slatkin, 1987).

Within species, dispersal may be biased towards certain individuals, which has consequences for a species' genetic diversity and population genetic structure. For example, in some species, female birds tend to disperse farther than males, while male mammals tend to disperse farther than females (sex-biased dispersal) (Greenwood, 1980; Trochet et al., 2016). While females form the core of societies in ants (and all social Hymenoptera), considerable variation exists among the dispersal abilities of males and reproductive females (Bourke \& Franks, 1995; Cronin, Molet, Doums, Monnin, \& Peeters, 2013; Hakala, Seppä, \& Helanterä, 2019; Helms, 2018; Jacobs \& Heinze, 2019; Keller, Peeters, \& Beldade, 2014). For example, some ant species have 
wingless individuals (females or males) that can move across scales of just a few meters, or winged individuals that vary in their ability or tendency to disperse long distances (over hundreds of meters). Typically, dispersal pattern and colony founding mode determine intraspecific population genetic patterns. For example, in species where queens do not fly, males may fly and be responsible for most long-distance dispersal (Berghoff, Kronauer, Edwards, \& Franks, 2008; Hakala et al., 2019). In other species, wingless males and winged females may experience inbreeding due to a lack of dispersal (Jacobs \& Heinze, 2019). In species with winged males and females, both sexes may contribute to long-distance dispersal, gene flow, and near panmictic population structure (Johansson, Seppä, Helanterä, Trontti, \& Sundström, 2018). On the other hand, some species with volant sexuals nevertheless show signatures of male-biased long-distance dispersal (Holzer, Keller, \& Chapuisat, 2009), especially in species with relatively large and fat-laden queens that produce their first offspring via metabolic stores (claustral founding) (Helms, 2018).

The fungus-gardening (attine) ants are common ants in low to mid latitudes of the western hemisphere (Branstetter et al., 2017; Nygaard et al., 2016; Seal \& Tschinkel, 2006). The ants depend on their fungal cultivar as their main nutritional source, and the fungus depends on the ants for propagation, survival, and dispersal. Virgin queens (gynes) are solely responsible for dispersal of the mutualistic fungi (vertical transmission) by storing it in an infrabuccal pocket prior to the nuptial flight (Huber, 1905; Mueller, 2002; Mueller, Schultz, Currie, Adams, \& Malloch, 2001). Thus, symbiotic fungal expansion and diversification is expected to be largely dependent on dispersal capabilities of the female ants. As a result, female-biased dispersal (or at least not male-biased dispersal) may be favored in attine ants; strict male-biased dispersal would conflict with the dispersal interests of the fungus (Mueller, 2002) by limiting the expansion and diversification of the fungal symbiont. However, any conflicts could be resolved by males and gynes having similar dispersal abilities. Additionally, gynes of most attines appear to be energetically cheap to produce and most do not found claustrally (Fernández-Marín, Zimmerman, \& Wcislo, 2004; Seal, 2009; Seal \& Tschinkel, $2007 \mathrm{~b}$ ); thus, attines might not be under selection to produce large, heavy gynes that are generally dispersallimited because of the energetic demands of flight (Helms, 2018). Consequently, the relatively lighter attine gynes may fly just as far as males, thus increasing expansion capabilities of the co-dispersed fungus.

Surprisingly, there have been very few studies that examine sex-biased dispersal and gene flow in fungusgardening ants, even though the molecular markers necessary to do so have been developed. For instance, microsatellite markers have been used to examine polyandry, polygyny, and population structure (Bekkevold, Frydenberg, \& Boomsma, 1999; Fjerdingstad \& Boomsma, 2000; Helmkampf, Gadau, \& Feldhaar, 2008; Kellner et al., 2013; Matthews, Rowan, Stone, Kellner, \& Seal, 2020; Murakami, Higashi, \& Windsor, 2000; Rabeling et al., 2013; Rabeling et al., 2011; Rabeling et al., 2014) and mitochondrial DNA (mtDNA) markers have been used to examine phylogeographic structure (i.e., female dispersal patterns) in several attine species (Cardoso, Cristiano, Tavares, Schubart, \& Heinze, 2015; Seal, Thiebaud, \& Mueller, 2015; Solomon, Bacci, Martins, Vinha, \& Mueller, 2008). While at least one study reported comparable dispersal abilities in both male and female Atta colombica, only a small portion of its known range was surveyed (Helmkampf et al., 2008). Indeed,Atta species are the only attines that exhibit claustral founding (Fernández-Marín \& Wcislo, 2005; Fernández-Marín et al., 2004; Hölldobler \& Wilson, 2011; Huber, 1905); it therefore remains possible that the large females (among the largest individual ants in the world) are not capable of flying as far as males.

In this study, we employ mtDNA markers and diploid microsatellite markers that were developed using whole genome sequencing (Matthews et al., 2020) to examine population structure, gene flow, and signatures of sex-biased dispersal in a fungus-gardening ant species, Trachymyrmex septentrionalis (McCook, 1881) . T. septentrionalis is distributed from Texas to Florida to Long Island, New York, with a center of genetic diversity found in northern Florida (Rabeling, Cover, Johnson, \& Mueller, 2007; Seal et al., 2015; Senula et al., 2019). Prior studies using mtDNA have shown significant phylogeographic structure across its range. For example, haplotypes are represented by phylogroups east and west of the Mississippi River, with western populations consisting of one clade whereas those found in the east are more diverse, consisting of at least three clades (Mikheyev, Vo, \& Mueller, 2008; Seal et al., 2015). A preliminary analysis of nuclear microsatellites supports this overall pattern - higher diversity in populations east of the Mississippi River relative 
to the west (Matthews et al., 2020).T. septentrionalis is one of the most common and abundant ant species in the longleaf pine forests of Florida whose populations appear to respond rapidly to annual variations in climate (especially rainfall) and local conditions (e.g., relief) and often move significant amounts of soil in the process (Seal \& Tschinkel, 2006, 2008, 2010; Tschinkel \& Seal, 2016). Therefore, understanding the population genetics of this species will help us understand the dispersal biology of an ecologically important symbiosis.

\section{MATERIALS AND METHODS}

\section{Study site and field methods}

Trachymyrmex septentrionalis colonies were found in Florida, USA. Florida is located entirely within the North American Coastal Plain, which is a global biodiversity hotspot owing to its unique geologic history and diverse ecosystems (Griffith, 1994; Noss, 2012; Noss et al., 2015). Samples were collected across two primary regions in Florida that correspond with known biogeographic breaks in the state (e.g., (Seal et al., 2015)); the panhandle (which included two distinct ranger districts within the Apalachicola National Forest and a nearby barrier island) and the peninsula, represented by samples collected in North Central Florida near Gainesville and in Central Florida near Orlando (Figure 1).

In the panhandle, the Apalachicola National Forest (ANF) is divided into two ranger districts that occur on either side of the Ochlockonee River: the Apalachicola Ranger District on the west and the Wakulla Ranger District on the east. The Apalachicola Ranger District (ARD) is comprised mainly of pine flatwood forest with high herbaceous cover, little relief, and a high water table (Abrahamson \& Harnett, 1990). Trachymyrmex septentrionalis colonies in pine flatwoods are restricted to 'habitat islands' of somewhat higher elevation (relative to the water table) and population sizes likely vary temporally as annual rainfall varies from drought to very wet (Seal \& Tschinkel, 2010). On the other hand, the Wakulla Ranger District (WRD) contains significant stands of sandhill forest (i.e., remnants of Pleistocene sand dunes; (Myers, 1990)) that are excessively drained and support many species associated with deserts (Brown, Stone, \& Carlisle, 1990). T. septentrionalis colonies are found throughout the sandhills, absent only from frequently inundated areas near ephemeral ponds. Unlike flatwoods populations, those found in sandhills do not likely fluctuate very much in size, at least with respect to rainfall (Seal \& Tschinkel, 2006, 2010). Both ranger districts are dominated and characterized by longleaf pine (Pinus palustris) and sandy soils. Located just south of the ANF, St. George Island is a sandy barrier island approximately $6 \mathrm{~km}$ from the mainland. Despite its low relief and susceptibility to hurricanes, the island contains several stands of pine forest on elevated regions (Gornish \& Miller, 2010; Huffman, Platt, \& Grissino-Mayer, 2004) which harbor several species typical of sandhills further inland, such as T. septentrionalis and the seed-harvesting antPogonomyrmex badius. The Florida peninsula is separated from the panhandle by the Suwanee River, a known biogeographic barrier to many species (including ants), owing to different soils and geological history (Brown et al., 1990; Richter et al., 2014; Strehl \& Gadau, 2004). Thus, the collections were made across multiple ecological gradients and potential dispersal barriers.

Trachymyrmex septentrionalis colonies were identified in the field by their distinctive and steep crescentshaped mounds, which are built up by ants piling excavated chamber soil (Seal \& Tschinkel, 2006). Individual worker ants were collected directly from colonies in 2013 and 2018 . All workers were preserved in $95 \%$ ethanol at $-20^{\circ} \mathrm{C}$ until DNA extraction. Only one individual worker per colony was used for sequencing. All relevant specimen information (e.g., collection date, region/location) can be found in Table S1.

\section{Microsatellite genotyping and genetic diversity}

We extracted genomic DNA from 64 individual T. septentrionalisworkers using a QIAamp DNA Micro Kit (QIAGEN). We implemented the M13-tail polymerase chain reaction (PCR) method (Schuelke, 2000), which involves three primers in the PCR reaction: forward primers (Matthews et al., 2020) with an M13-tail at the 5' end, an unlabeled reverse primer, and a universal M13 primer labeled with 6-FAM (6-carboxy-fluorescine) fluorescent dye. These were used to amplify nine microsatellite loci (Ts21, Ts25, Ts32, Ts33, Ts39, Ts41, Ts43, Ts46, Ts5) (Matthews et al., 2020). 
PCRs were performed in a $10 \mu \mathrm{L}$ mix containing $1 \mu \mathrm{L}$ of 10X PCR buffer (1.0X; Applied Biosystems), $1 \mu \mathrm{L}$ Bioline@ dNTP mix (1 mM each; $0.1 \mathrm{mM}$ as a proportion of the total), $1.5 \mu \mathrm{L}$ of $25 \mathrm{mM} \mathrm{MgCl}_{2}(3.75 \mathrm{mM}$; Applied Biosystems), $0.5 \mu \mathrm{L}$ of $20 \mu \mathrm{M}$ BSA ( $1 \mu \mathrm{M}$; New England Biolabs), $0.3 \mu \mathrm{L}$ of $2 \mu \mathrm{M}$ tag labeled primer $(0.06 \mu \mathrm{M}$; forward primer with M13 tag), $0.6 \mu \mathrm{L}$ of a $2 \mu \mathrm{M}$ universal dye-labeled primer $(0.12 \mu \mathrm{M}$; FAM label with M13 tag), $1 \mu \mathrm{L}$ of $2 \mu \mathrm{M}$ unlabeled primer $(0.2 \mu \mathrm{M}$; reverse primer), $0.1 \mu \mathrm{L}$ of Taq polymerase (0.5 U; Applied Biosystems), and $1 \mu \mathrm{L}$ of DNA template. Nuclease-free water was used to make up the remaining volume. The following thermocycling profile was used on an Eppendorf Mastercycler: initial denaturation of $4 \mathrm{~min}$ at $95^{\circ} \mathrm{C}$, followed by 25 (or 30) cycles of $30 \mathrm{~s}$ at $95^{\circ} \mathrm{C}, 45 \mathrm{~s}$ at the primer-specific annealing temperature found by a temperature gradient program, $45 \mathrm{~s}$ at $72^{\circ} \mathrm{C}$, then 8 cycles of $30 \mathrm{~s}$ at $95^{\circ} \mathrm{C}, 45 \mathrm{~s}$ at $53^{\circ} \mathrm{C}$, and 45 $\mathrm{s}$ at $72^{\circ} \mathrm{C}$, followed by a final extension of $5 \mathrm{~min}$ at $72^{\circ} \mathrm{C}$. Diluted PCR products were run on an Applied Biosystems 3730 Genetic Analyzer and fragments were sized with LIZ600 size standard at the University of Texas at Austin DNA Sequencing Facility in Austin, Texas, USA. We scored alleles using Geneious v10.2.3 (Kearse et al., 2012).

For each locus, we used GenAlEx v6.5 (Peakall \& Smouse, 2006; Peakall \& Smouse, 2012) to estimate the number of alleles $(K)$, observed and expected heterozygosity $\left(\mathrm{H}_{\mathrm{o}}\right.$ and $\left.\mathrm{H}_{\mathrm{e}}\right)$, and the probability of identity (PI; the probability of two independent samples having the same genotype). We assessed deviations from Hardy-Weinberg equilibrium (HWE) expectations using GENEPOP v4.2 (Rousset, 2008) across each locus for the overall dataset, as well as across each locus within each population. GENEPOP was also used to test for linkage disequilibrium (LD) across all pairs of loci.

\section{Amplification and sequencing of mtDNA}

In order to augment our microsatellite data, we included mtDNA previously sequenced from Seal et al. (2015; $\mathrm{n}=61)$ and sequenced new samples directly for this study $(\mathrm{n}=26)$. A total of 55 samples had both microsatellite and mtDNA sequenced (Table S1). Again, DNA was extracted from whole individual ants using a QIAamp DNA Micro Kit (QIAGEN), and a 779-bp sequence was obtained from the COI-tRNA Leucine-COII region of mtDNA. We used the following primers: C1J2195 (alias CO1-RLR; 5'-TTGATTTTTTGGTCATCCAGAAGT-3'); and C2-N-3661 (alias Barbara; 5'CCACAAATTTCTGAACATTGACCA-3'(Simon et al., 1994)). PCR mixtures and cycling profiles were identical to Seal et al. (2015). PCR products were then purified and sequenced at the University of Texas at Austin's DNA Sequencing Facility on an Applied Biosystems 3730 DNA Analyzer. Chromatograms were visually checked and resolved in Geneious v10.2.3 (Kearse et al., 2012), and sequences were aligned using MEGA v6.06 (Tamura, Stecher, Peterson, Filipski, \& Kumar, 2013) using the ClustalW algorithm (Thompson, Higgins, \& Gibson, 1994). New sequences are deposited into GenBank under accession numbers MN088095-MN088120 (Table S1). mtDNA is known to have several properties that make evolutionary conclusions problematic, such as pseudogenes or nuclear insertions (numts) (Beckenbach, 2009; Cristiano, Cardoso, \& Fernandes-Salomao, 2014; Martins et al., 2007; Toews \& Brelsford, 2012). Therefore, we examined for stop codons in our sequences (other than at the COI-tRNA Leucine transitions) (Seal et al., 2015). Sequences were also long and frequently readable at $>800 \mathrm{bp}$. Two primary advantages of mtDNA sequences are that 1) sequences can be readily obtained and 2) the problems associated with mtDNA are understood and can be easily examined, whereas the problems associated with nuclear markers are more uncertain (Bowen et al., 2014; Moreau, 2009). Moreover, a preliminary examination of the microsatellite markers of T. septentrionalisused in this study supported one of the main findings of mtDNA-based studies in this species: pronounced genetic differentiation across the Mississippi River Valley (Matthews et al., 2020), thus making it unlikely that the COI sequences analyzed were numts, which usually lack variation because of purifying selection in nuclear genomes (Martins et al., 2007). Therefore, mtDNA sequences in this species are likely robust genetic tools (Matthews et al., 2020; Mikheyev et al., 2008; Seal et al., 2015).

\section{Population genetic analyses}

\section{Microsatellites}

We measured population genetic structure by Analysis of Molecular Variance (AMOVA) (Excoffier, Smouse, 
\& Quattro, 1992) and by pairwise Fst values between populations in Arlequin v3.5.2.2 (Excoffier \& Lischer, 2010). Significance was tested using 1,000 permutations. We generated several subsets to examine signatures of population differentiation related to the varying ecologies and potential barriers to dispersal across our collection sites. Specifically, our subsets were: a) all regions; b) all regions with the island excluded; c) ANF panhandle regions only (i.e., ARD and WRD); d) peninsular regions only (i.e., North Central near Gainesville and Central near Orlando); and e) ANF regions as one collective region and peninsular regions as one collective region. For each subset, we adjusted the allowed missing data (from 0.15 to 0.5 ) in order to include all nine loci in all analyses.

To further assess population genetic structure, we used the Bayesian clustering algorithm implemented through STRUCTURE v2.3.4 (Pritchard, Stephens, \& Donnelly, 2000), which uses allele frequency data to assign individuals into genetic clusters $(\mathrm{K})$. These analyses were executed with no prior population information and under the admixture model with correlated allele frequencies. In order to determine $\mathrm{K}$, we assessed $\mathrm{K}=1$ through $\mathrm{K}=10$ with default parameters. To explore each $\mathrm{K}$ value, we performed 10 replicates with a burnin value of 50,000 and 500,000 MCMC iterations. We determined the optimal $\mathrm{K}$ value by assessing the maximum likelihood values and $\Delta \mathrm{K}$ (Evanno, Regnaut, \& Goudet, 2005) implemented in Structure Harvester v0.6.94 (Earl \& von Holdt, 2012). We then averaged the 10 STRUCTURE replicates for the optimal K through the CLUMPAK pipeline (Kopelman, Mayzel, Jakobsson, Rosenberg, \& Mayrose, 2015) and visualized the results in DISTRUCT v1.1 (Rosenberg, 2004).

We performed Mantel tests to test whether genetic distances correlate with geographic distance (isolation by distance; IBD). We generated several subsets to test for IBD. Specifically, we considered the following: a) all sampling sites across all regions; b) all sampling sites excluding the island; c) all sampling sites within the ANF; and d) all sampling sites within the peninsula. For measures of genetic distances, we used pairwise Fst values obtained from Arlequin and linearized them as Fst/(1-Fst) (Rousset, 1997). Negative Fst values, if present, were set to zero. Otherwise, the absolute difference between values would be inflated, when in actuality they are effectively zero (i.e., no genetic differentiation). We used Geographic Distance Matrix Generator v1.2.3 (Ersts, 2013) to generate pairwise geographic distances (in km) from the GPS coordinates of the sampling sites. We implemented Mantel tests using the ade4 package (Dray \& Dufour, 2007) in R (Team, 2018) with 9,999 permutations.

\section{Mitochondrial DNA}

Using the COI mtDNA alignment, we examined haplotype diversity and calculated basic genetic polymorphism statistics and across regions and within regions using DNAsp v6 (Rozas et al., 2017). We then reconstructed a haplotype network for the COI data $(\mathrm{n}=87$; combined samples from Seal et al. (2015) and new sequences directly from this study) using the TCS method (Clement, Posada, \& Crandall, 2000) in PopArt v1.7 (Leigh \& Bryant, 2015).

\section{RESULTS}

\section{Genetic diversity of microsatellite DNA}

The mean number of alleles per locus across nine loci in regions of Florida was 18.9. The mean observed heterozygosity was 0.688 , while the mean expected heterozygosity was higher at a value of 0.859 (Table 1). After Bonferroni correction for multiple comparisons across all regions, four of the nine loci showed deviations from expectations under HWE (Table 1). However, by region and locus, only four HWE tests were significant after Bonferroni corrections and no loci deviated in more than two regions (Table 1). Therefore, we retained all nine loci for downstream analyses. There were no cases of linkage disequilibrium detected for any pair of loci (raw genotypic data for microsatellites are available in Table S2).

\section{Population genetic analyses}

\section{Microsatellites}

Overall, AMOVAs did not reveal significant population differentiation (overall Fst values were between 0.000 
and 0.035 and all associated Fst p-values were $>0.05$ ). Thus, the amount of genetic variation attributable to differences between the assigned population subsets was low and insignificant; most of the genetic differentiation occurred within and among individuals (Table S3). Alternatively, according to our STRUCTURE results, there are two distinct genetic clusters $(K=2)$ in our dataset, providing evidence for genetic differentiation across Florida with signatures of gene flow between clusters. Specifically, the samples from St. George Island were largely assigned to one cluster. Likewise, the samples from the peninsula region were largely assigned to another single cluster with minimal admixture. The samples from the ANF appear to have substantial (nearly $50 \%$ overall) admixture of alleles associated with the peninsula and St. George Island clusters (Figure 2).

Finally, based on results of the Mantel tests of the association between genetic distance and geographic distance, we found weak to little evidence of IBD across the different subsets (Figure 3). Thus, the amount of genetic variation explained by geographic distance is low, suggesting that the genetic differentiation of our samples is continuous across geography rather than illustrating discrete populations separated by specific barriers.

\section{Mitochondrial DNA}

In contrast to the diploid microsatellite markers, mtDNA markers indicated pronounced population differentiation. There were two distinct haplotype clades found in the panhandle and one in the peninsula. Three specimens collected in the North Central peninsula (Gainesville) appeared to be most similar to those found in the panhandle, however, even these were genetically unique (Figure 4). Across the combined 87 samples, there were 38 mitochondrial haplotypes identified and were defined by 71 polymorphic sites, which consisted of 33 singleton variable sites and 38 parsimony informative sites. Overall haplotype diversity was high and overall nucleotide diversity was low, with the same being true within each region (the Central region is an exception to high haplotype diversity), suggesting a recent population expansion (Table 2).

\section{DISCUSSION}

The goals of this study were to examine the population structure, gene flow, and signatures of sex-biased dispersal in a fungus-gardening ant species across several ecological gradients in Florida, USA. Overall, our results suggest that most long-distance dispersal is conducted by males. Specifically, females appear to have more limited dispersal as the mtDNA haplotypes are strongly geographically clustered (Figure 4). There were two COI clades found primarily in the Florida panhandle (Ts Clade I and Ts Clade II) and one that was restricted to the Florida peninsula (Ts Clade III). There were only three ants collected on the peninsula that somewhat clustered with panhandle ants: one with Ts Clade I (however, this specimen was separated from the Ts Clade I by 32 mutation steps) and two with Ts Clade II, separated by 12 mutation steps. These three ants were notably collected in North Central Florida, near Gainesville, geographically closer to the panhandle than the samples collected in Central Florida near Orlando. In contrast to mtDNA data, biparental microsatellite markers suggest significant gene flow across Florida (approximately 360km, linear distance between the Central region in Orlando and St. George Island, Florida) and minimal spatial structure (Figures 2 and 3). These results indicate considerable admixture of microsatellite alleles across the range of this study, which considering the geographic clustering of mtDNA COI sequences, likely arise from male movement. Together, these results suggest that males are responsible for most long-distance dispersal while females (and concomitantly, their co-dispersed fungal symbionts; (Tesson et al., 2015)) do not disperse very far. This result was surprising since $T$. septentrionalisqueens are not relatively large nor especially endowed with fat stores, which could impact their flying ability (Helms, 2018; Seal, 2009; Seal \& Tschinkel, 2007b).

It is not clear how much of a barrier that rivers present to females since we did find evidence of some trans-river female dispersal; however, the distance that females seem to move across rivers is much shorter relative to the distance males appear to disperse. The Suwannee River may be an important barrier to female dispersal, though not impenetrable since two peninsular haplotypes (in three individuals) were found clustered with the two panhandle clades (Figure 4). Conversely, the Ochlocknee River in the panhandle may 
not be a significant dispersal barrier to either sex considering the extensive admixture of microsatellite alleles (Figure 2) and shared haplotype clades (Ts Clades I and II; and even identical haplotypes in some cases) in both the ARD and WRD (Figure 4). The latter finding is surprising considering the differing ecologies and environments (i.e., frequently flooded flatwoods in the ARD and dry, xeric sandhills in the WRD). That being said, the finding of reduced genetic diversity in the ARD relative to the WRD (Table 2) could suggest recent expansion in the WRD. As a result, on small scales (10s of kilometers), T. septentrionalis appears to be a very mobile species, capable of rapid population growth and extensive dispersal capabilities, but there are limits to their expansion abilities across larger scales ( $>100$ s of kilometers). Possible explanations for this conclusion could be related to Pleistocene bottlenecks and then subsequent expansion, and a subsequent time lag in the expansion of COI haplotypes. Therefore, it would appear likely that males have a greater dispersal capability than females. Field studies measuring the variation in flight distance within and between sexes could further inform our results.

Evidence is currently lacking as to whether male-biased dispersal is the general rule in the tribe Attini. This is surprising considering how important female dispersal is for the range expansion and ultimately evolution of the fungal symbiont (Mueller et al., 2001). For example, the basal neoattine Mycetophylax simplex exhibited relatively minor mtDNA (COI) variation across its range in Brazilian Atlantic Forest (Cardoso et al., 2015), which suggests that females are capable of long-distance dispersal. However, as a lower attine (i.e., an early branching lineage of attini), Mycetophylaxlikely has smaller queens than Trachymyrmex sensu lato ants and other members of the so-called 'higher attini' (Seal, 2009); thus, the energetic cost of dispersal for Mycetophylax compared to Trachymyrmex sensu lato could possibly be lower. As another example, Mycocepurus smithii indicated stronger gene flow and little spatial structure in populations across the Panamanian isthmus (inferred from microsatellites) unlike their fungal symbionts that were more spatially structured, though the study did not also employ mtDNA markers like the present study (Kellner et al., 2013). While spatially structured fungal symbionts could point to limited female dispersal and long-distance male dispersal like we found with T. septentrionalis, males are rare if not absent in M. smithii, which exhibit thelytokous parthenogenesis in Panama (Kellner et al., 2013). Thus, M. smithii female movement (and some level of disruption to vertical fungi transmission) likely explains the patterns in central Panama. While lower attines such as Mycetophylax and Mycocepuruscultivate fungi that are likely capable of independent life, fungi grown by higher attini such as Trachymyrmex and Atta are not (Schultz \& Brady, 2008). Solomon et al. (2008) reported mtDNA (COI) clusters in three Atta species across continental scales, which suggests limited female dispersal, but did not examine whether males were capable of dispersing longer distances. Interestingly, ddRADseq (i.e., diploid markers) in Atta texanashowed evidence of spatial structure and isolation by distance across a north-south gradient in Texas $(850 \mathrm{~km})$. Though fungal symbionts also illustrate significant north-south differentiation in this species, the patterns are not concordant with their host ants (Mueller, Mikheyev, Solomon, \& Cooper, 2011; Smith et al., 2019), which could indicate independent/differential dispersal patterns of males, females, and fungal symbionts via unknown mechanisms.

Our results support greater dispersal abilities in male T. septentrionalis than females. Consequently, this suggests that the dispersal abilities of the vertically transmitted symbiotic fungus (and further associated microbial symbionts (Ishak et al., 2011; Ronque, Lyra, Migliorini, Bacci, \& Oliveira, 2020)) are likely also limited and thus also exhibits spatial structure, unless the fungus also has the ability of independent dispersal as suggested in A. texana (Smith et al., 2019). Limited female and symbiont co-dispersal could represent a significant bottleneck to fungal diversification (and associated microbes). Bottlenecks are a common feature among vertically transmitted symbionts, which generally exhibit eroded genetic variation and reduced genomes compared to horizontally exchanged relatives (Bennett, McCutcheon, MacDonald, Romanovicz, \& Moran, 2014; Douglas, 2010; Helms, Ijelu, \& Haddad, 2019; Nikoh, Hosokawa, Oshima, Hattori, \& Fukatsu, 2011). Bottlenecks may not only influence population demographics but also the adaptive abilities of codispersed symbionts under varying environments. Consequently, the overall coevolutionary patterns and associations observed in the fungus-farming ant symbiosis may be constrained by limited female dispersal especially in the higher attini that are characterized by obligate symbionts and large-bodied, fatter queens.

The approximately 49 ant species in the genus formerly known as Trachymyrmex (now split into 3 genera 
(Solomon et al., 2019)) grow conservatively 4-5 phylotypes of fungi (Ješovnik et al., 2017; Luiso, Kellner, Matthews, Mueller, \& Seal, 2020; Solomon et al., 2019). One possible explanation is that ant host diversification in these derived lineages has happened at a faster rate than their fungal symbionts because of limited female ant dispersal. Whether attine ants and their fungal symbionts have different evolutionary (or expansion) rates is currently unknown. The most recent genome-level examinations suggested that attine fungal genomes have lower diversity of metabolic genes compared to free-living fungi; however, this was based on transcriptomes (measures of gene expression) as we lack fully annotated attine fungal genomes because attine fungi are functionally polyploid (Kooij, Aanen, Schiott, \& Boomsma, 2015; Kooij, Poulsen, Schiøtt, \& Boomsma, 2015; Nygaard et al., 2016). Alternatively, since neither ant nor fungi have to evolve at similar rates, reduced fungal lineage diversity could be due to higher evolutionary and subsequent extinction rates among the fungi, such that fungal diversification may occur more rapidly with ants adopting novel fungal strains and discarding others as climate and parasite pressure change the outcome of the interaction (Mehdiabadi, Hughes, \& Mueller, 2006; Seal \& Mueller, 2014; Seal, Schiøtt, \& Mueller, 2014; Seal \& Tschinkel, 2007a). Furthermore, some phylogenetic analyses suggest that the fungal lineages typically grown by leaf-cutter ants (i.e., Clade A fungi grown by Atta andAcromyrmex ) (Mueller et al., 2018) are younger than the ant lineages (Mikheyev, Mueller, \& Abbot, 2010; Nygaard et al., 2016) which suggests a recent domestication event. However, analyses of more recent datasets have called this conclusion into question since some non-leaf-cutting ants grow Clade A fungi (Mueller et al., 2017; Mueller et al., 2018; Schultz et al., 2015), indicating that the fungi may have been around for as long as the less derived Trachymyrmex ants. In conclusion, a greater understanding of the dispersal biology of these species could vastly improve our ability to understand and ultimately predict how host and symbiont populations expand and evolve across larger geographic and macroevolutionary scales.

\section{ACKNOWLEDGEMENTS}

The work was supported by a National Science Foundation grant to JNS (CAREER, IOS-152822) and KK (DEB-1354629). Travel to Florida was also funded by a UT-Tyler Internal Research Grant to JNS. We thank Walter Tschinkel for providing logistical support while collecting in North Florida. Joshua King and Andrea Lucky provided T. septentrionalisspecimens from the Orlando and Gainesville, Florida areas, respectively. This is paper No. 4 of the Ant Symbiosis Laboratory.

\section{REFERENCES}

Abrahamson, W. G., \& Harnett, D. C. (1990). Pine flatwoods and dry prairies. In R. L. Myers \& J. J. Ewel (Eds.), The Ecosystems of Florida (pp. 103-149). Orlando, FL: The University of Central Florida.

Beckenbach, A. (2009). Numts and mitochondrial pseudogenes. Myrmecological News, 12 , 217-218.

Bekkevold, D., Frydenberg, J., \& Boomsma, J. J. (1999). Multiple mating and facultative polygyny in the Panamanian leafcutter ant Acromyrmex echinatior. Behavioral Ecology and Sociobiology, 46, 103-109.

Bennett, G. M., McCutcheon, J. P., MacDonald, B. R., Romanovicz, D., \& Moran, N. A. (2014). Differential genome evolution between companion symbionts in an insect-bacterial symbiosis. mBio, 5 (5), e01697-01614. doi:10.1128/mBio.01697-14

Berghoff, S. M., Kronauer, D., Edwards, K., \& Franks, N. (2008). Dispersal and population structure of a New World predator, the army ant Eciton burchellii .Journal of Evolutionary Biology, 21 , 1125-1132.

Bourke, A. F. G., \& Franks, N. R. (1995). Social evolution in ants . Princeton, New Jersey: Princeton University Press.

Bowen, B., Shanker, K., Yasuda, N., Malay, M., von der Heyden, S., Paulay, G., . . . Toonen, R. (2014). Phylogeography unplugged: comparative surveys in the genomic era.Bulletin of Marine Science, 90 (1), $13-46$.

Branstetter, M. G., Jesovnik, A., Sosa-Calvo, J., Lloyd, M. W., Faircloth, B. C., Brady, S. G., \& Schultz, T. R. (2017). Dry habitats were crucibles of domestication in the evolution of agriculture in ants. Proceedings 
of the Royal Society B, 284 (1852). doi:10.1098/rspb.2017.0095

Brown, R. B., Stone, E. L., \& Carlisle, V. W. (1990). Soils. In R. L. Myers \& J. J. Ewel (Eds.),Ecosystems of Florida (pp. 35-69). Orlando: University of Central Florida Press.

Cardoso, D. C., Cristiano, M. P., Tavares, M. G., Schubart, C. D., \& Heinze, J. (2015). Phylogeography of the sand dune ant Mycetophylax simplex along the Brazilian Atlantic Forest coast: remarkably low mtDNA diversity and shallow population structure. BMC Evolutionary Biology, 15 (1), 106. doi:10.1186/s12862-0150383-4

Clark, R. W., Brown, W. S., Stechert, R., \& Zamudio, K. R. (2010). Roads, interrupted dispersal, and genetic diversity in timber rattlesnakes. Conserv Biol, 24 (4), 1059-1069. doi:10.1111/j.1523-1739.2009.01439.x

Clement, M., Posada, D., \& Crandall, K. A. (2000). TCS: a computer program to estimate gene genealogies. Molecular Ecology, 9 , 1657-1659.

Clobert, J., Baguette, M., Benton, T. G., \& Bullock, J. M. (Eds.). (2012). Dispersal Ecology and Evolution . Oxford, United Kingdom: Oxford University Press.

Cristiano, M., Cardoso, D., \& Fernandes-Salomão, T. M. (2014). Could pseudogenes be widespread in ants? Evidence of numts in the leafcutter ant Acromyrmex striatus(Roger, 1863) (Formicidae: Attini). Comptes Rendus Biologies, 337, 78-85.

Cronin, A. L., Molet, M., Doums, C., Monnin, T., \& Peeters, C. (2013). Recurrent evolution of dependent colony foundation across eusocial insects. Annu Rev Entomol, 58 , 37-55. doi:10.1146/annurev-ento-120811153643

DiBlasi, E., Johnson, K. P., Stringham, S. A., Hansen, A. N., Beach, A. B., Clayton, D. H., \& Bush, S. E. (2018). Phoretic dispersal influences parasite population genetic structure. Mol Ecol, 27 (12), 2770-2779. doi:10.1111/mec.14719

Doña, J., Osuna-Mascaró, C., Johnson, K. P., Serrano, D., Aymí, R., \& Jovani, R. (2019). Persistence of single species of symbionts across multiple closely-related host species. Scientific Reports, 9 (1), 17442. doi:10.1038/s41598-019-54015-2

Douglas, A. E. (2010). The Symbiotic Habit . Princeton, New Jersey: Princeton University Press.

Dray, S., \& Dufour, A.-B. (2007). The ade4 Package: Implementing the Duality Diagram for Ecologists.2007, 22 (4), 20. doi:10.18637/jss.v022.i04

Earl, D. A., \& von Holdt, B. M. (2012). STRUCTURE HARVESTER: a website and program for visualizing STRUCTURE output and implementing the Evanno method. .Conservation Genetics Resources, 4 (2), 359-361. doi:doi: 10.1007/s12686-011-9548-7

Ellis, V. A., Collins, M. D., Medeiros, M. C., Sari, E. H., Coffey, E. D., Dickerson, R. C., . . Ricklefs, R. E. (2015). Local host specialization, host-switching, and dispersal shape the regional distributions of avian haemosporidian parasites. Proc Natl Acad Sci U S A, 112 (36), 11294-11299. doi:10.1073/pnas.1515309112

Ersts, P. (2013). Geographic Distance Matrix Generator. American Museum of Natural History, Center for Biodiversity and Conservation: Available from http://biodiversityinformatics.amnh.org/open_source/gdmg.

Evanno, G., Regnaut, S., \& Goudet, J. (2005). Detecting the number of clusters of individuals using the software STRUCTURE: a simulation study. Mol Ecol, 14 (8), 2611-2620. doi:10.1111/j.1365-294X.2005.02553.x

Excoffier, L., \& Lischer, H. (2010). Arlequin suite ver 3.5: A new series of programs to perform population genetics analyses under Linux and Windows. Molecular Ecology Resources, 10 , 564-567. 
Excoffier, L., Smouse, P., \& Quattro, J. (1992). Analysis of molecular variance inferred from metric distances among DNA haplotypes: application to human mitochondrial DNA restriction data. Genetics, 131 (2), 479491.

Fernández-Marín, H., \& Wcislo, W. T. (2005). Production of minima workers by gynes of Atta colombicaGuérin-Ménéville (Hymenoptera: Formicidae: Attini) that lack a fungal pellet. Journal of the Kansas Entomological Society, 78 (3), 290-292.

Fernández-Marín, H., Zimmerman, J. K., \& Wcislo, W. T. (2004). Ecological traits and evolutionary sequence of nest establishment in fungus-growing ants (Hymenoptera, Formicidae, Attini. Biological Journal of the Linnean Society, 81, 39-48.

Fjerdingstad, E. J., \& Boomsma, J. J. (2000). Queen mating frequency and relatedness in young Atta sexdens colonies. Insectes Sociaux, 47 , 354-356.

Gornish, E. S., \& Miller, T. E. (2010). Effects of storm frequency on dune vegetation. Global Change Biology, 16 (10), 2668-2675. doi:10.1111/j.1365-2486.2009.02144.x

Greenwood, P. J. (1980). Mating systems, philopatry and dispersal in birds and mammals. Animal Behaviour, 28 (4), 1140-1162. doi:https://doi.org/10.1016/S0003-3472(80)80103-5

Griffith, G. E., Omernik, J.M., Rohm, C.W., and Pierson, S.M. ( 1994). Florida regionalization project . Corvallis, Oregon: National Health and Environmental Effects Research Laboratory.

Hakala, S. M., Seppä, P., \& Helanterä, H. (2019). Evolution of dispersal in ants (Hymenoptera: Formicidae): a review on the dispersal strategies of sessile superorganisms. Myrmecological News, 29, 35-55.

Haye, P. A., Segovia, N. I., Muñoz-Herrera, N. C., Gálvez, F. E., Martínez, A., Meynard, A., .. . Faugeron, S. (2014). Phylogeographic Structure in Benthic Marine Invertebrates of the Southeast Pacific Coast of Chile with Differing Dispersal Potential. PLoS ONE, 9 (2), e88613. doi:10.1371/journal.pone.0088613

Helmkampf, M., Gadau, J., \& Feldhaar, H. (2008). Population and sociogenetic structure of the leaf-cutter ant Atta colombica (Formicidae, Myrmecinae). Insectes Sociaux, 55 , 434-442.

Helms, J. (2018). The flight ecology of ants (Hymenoptera: Formicidae). Myrmecological News, 26 , 19-30.

Helms, J., Ijelu, S. E., \& Haddad, N. M. (2019). Range expansion in an introduced social parasite-host species pair. Biological Invasions, 21 (8), 2751-2759.

Hölldobler, B., \& Wilson, E. O. (2011). The Leafcutter Ants . New York: W.W. Norton.

Holzer, B., Keller, L., \& Chapuisat, M. (2009). Genetic clusters and sex-biased gene flow in a unicolonial Formica ant. BMC Evolutionary Biology, 9 , 69-69. doi:10.1186/1471-2148-9-69

Huber, J. (1905). Über die Koloniengründung bei Atta sexdens . Biologisches Centralblatt, 25 (18), 606-635.

Huffman, J., Platt, W., \& Grissino-Mayer, H. (2004). Fire history of a barrier island slash.Natural Areas Journal, 24, 259-268.

Ishak, H., Miller, J., Sen, R., Dowd, S. E., Meyer, E., \& Mueller, U. G. (2011). Microbiomes of ant castes implicate new microbial roles in the fungus-growing ant Trachymyrmex septentrionalis . 1, 204.

Jacobs, S., \& Heinze, J. (2019). Population and colony structure of an ant with territorial males, Cardiocondyla venustula. BMC Evolutionary Biology, 19 (1), 115. doi:10.1186/s12862-019-1448-6

Ješovnik, A., Sosa-Calvo, J., Lloyd, M. W., Branstetter, M. G., Fernández, F., \& Schultz, T. R. (2017). Phylogenomic species delimitation and host-symbiont coevolution in the fungus-farming ant genus Sericomyrmex Mayr (Hymenoptera: Formicidae): ultraconserved elements (UCEs) resolve a recent radiation.Systematic Entomology, 42 (3), 523-542. doi:doi:10.1111/syen.12228 
Johansson, H., Seppä, P., Helanterä, H., Trontti, K., \& Sundström, L. (2018). Weak population structure in the ant Formica fusca. PeerJ, 6 , e5024-e5024. doi:10.7717/peerj.5024

Kearse, M. M., R., Wilson, A., Stones-Havas, S., Cheung, M., Sturrock, S., Buxton, S., . . Drummond, A. (2012). Geneious Basic: an integrated and extendable desktop software platform for the organization and analysis of sequence data.Bioinformatics, 28 (2), 1647-1649.

Keller, R. A., Peeters, C., \& Beldade, P. (2014). Evolution of thorax architecture in ant castes highlights trade-off between flight and ground behaviors. Elife, 3 , e01539. doi:10.7554/eLife.01539

Kellner, K., Fernández-Marín, H., Ishak, H. D., Sen, R., Linksvayer, T. A., \& Mueller, U. G. (2013). Coevolutionary patterns and diversification of ant-fungus associations in the asexual fungus-farming ant Mycocepurus smithii in Panama. Journal of Evolutionary Biology, 26 (6), 1353-1362.

Kooij, P. W., Aanen, D. K., Schiott, M., \& Boomsma, J. J. (2015). Evolutionarily advanced ant farmers rear polyploid fungal crops. J Evol Biol, 28 (11), 1911-1924. doi:10.1111/jeb.12718

Kooij, P. W., Poulsen, M., Schiøtt, M., \& Boomsma, J. J. (2015). Somatic incompatibility and genetic structure of fungal crops in sympatric Atta colombica andAcromyrmex echinatior leaf-cutting ants. Fungal Ecology, 18 , 10-17.

Kopelman, N. M., Mayzel, J., Jakobsson, M., Rosenberg, N. A., \& Mayrose, I. (2015). Clumpak: a program for identifying clustering modes and packaging population structure inferences across K. Mol Ecol Resour, 15 (5), 1179-1191. doi:10.1111/1755-0998.12387

Leigh, J. W., \& Bryant, D. (2015). popart: full-feature software for haplotype network construction. Methods in Ecology and Evolution, 6 (9), 1110-1116. doi:10.1111/2041-210X.12410

Luiso, J., Kellner, K., Matthews, A. E., Mueller, U. G., \& Seal, J. N. (2020). High diversity and multiple invasions to North America by fungi grown by the northern-most Trachymyrmex and Mycetomoellerius ant species.Fungal Ecology, 44 , 100878. doi:10.1016/j.funeco.2019.100878

Manel, S., Schwartz, M. K., Luikart, G., \& Taberlet, P. (2003). Landscape genetics: combining landscape ecology and population genetics. Trends in Ecology $\mathscr{E}$ Evolution, 18 (4), 189-197. doi:https://doi.org/10.1016/S0169-5347(03)00008-9

Martins, J., Solomon, S., Mikheyev, A., Mueller, U., Ortiz, A., \& Bacci, M. (2007). Nuclear mitochondriallike sequences in ants: evidence from Atta cephalotes (Formicidae: Attini). Insect Molecular Biology, 16 (6), 777-784.

Matthews, A. E., Rowan, C., Stone, C., Kellner, K., \& Seal, J. N. (2020). Development, characterization, and cross-amplification of polymorphic microsatellite markers for North American Trachymyrmex and Mycetomoellerius ants. BMC Research Notes, 13 (1), 173. doi:10.1186/s13104-020-05015-3

Mehdiabadi, N. J., Hughes, B., \& Mueller, U. G. (2006). Cooperation, conflict, and coevolution in the attine ant-fungus symbiosis. Behavioral Ecology, 17 (2), 291-296.

Mikheyev, A. S., Mueller, U. G., \& Abbot, P. (2010). Comparative dating of attine ant and lepiotaceous cultivar phylogenies reveals coevolutionary synchrony and discord. The American Naturalist, 175 (6), E126E123.

Mikheyev, A. S., Vo, T. L., \& Mueller, U. G. (2008). Phylogeography of post-Pleistocene population expansion in a fungus-gardening ant and its microbial mutualists. Molecular Ecology, 17 (20), 4480-4488.

Moreau, C. S. (2009). Inferring ant evolution in the age of molecular data (Hymenoptera: Formicidae).Myrmecological News, 12 , 201-210.

Mueller, U. (2002). Ant versus fungus versus mutualism: ant-cultivar conflict and the deconstruction of the attine ant-fungus symbiosis. The American Naturalist, 160 , s67-s98. 
Mueller, U., Ishak, H., Bruschi, S., Smith, C., Herman, J., Solomon, S., . . Bacci, M., Jr. (2017). Biogeography of mutualistic fungi cultivated by leafcutter ants.Mol Ecol, 26 (24), 6921-6937. doi:10.1111/mec.14431

Mueller, U., Kardish, M., Ishak, H., Wright, A., Solomon, S., Bruschi, S., . . . Bacci, M. (2018). Phylogenetic patterns of ant-fungus associations indicate that farming strategies, not only a superior fungal cultivar, explain the ecological success of leafcutter ants. Molecular Ecology, 27 (10), 2414-2434. doi:doi:10.1111/mec.14588

Mueller, U., Mikheyev, A., Solomon, S., \& Cooper, M. (2011). Frontier mutualism: coevolutionary patterns at the northern range limit of the leaf-cutter ant-fungus symbiosis.Proceedings of the Royal Society B, 278 (1721), 3050-3059. doi:10.1098/rspb.2011.0125

Mueller, U., Schultz, T., Currie, C., Adams, R., \& Malloch, D. (2001). The origin of the attine ant-fungus mutualism. The Quarterly Review of Biology, 76 (2), 169-197.

Murakami, T., Higashi, S., \& Windsor, D. (2000). Mating frequency, colony size, polyethism and sex ratio in fungus-growing ants (Attini). Behavioral Ecology and Sociobiology, 48 (4), 276-284.

Myers, R. L. (1990). Scrub and high Pine. In R. L. Myers \& J. J. Ewel (Eds.), The Ecosystems of Florida (pp. 150-193). Orlando, FL: The University of Central Florida.

Nikoh, N., Hosokawa, T., Oshima, K., Hattori, M., \& Fukatsu, T. (2011). Reductive Evolution of Bacterial Genome in Insect Gut Environment. Genome Biology and Evolution, 3 , 702-714. doi:10.1093/gbe/evr064

Noss, R. (2012). Forgotten grasslands of the South : Island Press.

Noss, R., Platt, W., Sorrie, B., Weakley, A., Means, D. B., Costanza, J., \& Peet, R. K. (2015). How global biodiversity hotspots may go unrecognized: lessons from the North American Coastal Plain. Diversity and Distributions, 21 (2), 236-244.

Nygaard, S., Hu, H., Li, C., Schiøtt, M., Chen, Z., Yang, Z., . . Boomsma, J. J. (2016). Reciprocal genomic evolution in the ant-fungus agricultural symbiosis. Nature Communications, 7 , 12233.

Peakall, R., \& Smouse, P. E. (2006). GenAlEx 6: genetic analysis in Excel. Population genetic software for teaching and research. Mol Ecol Notes, 6 (1), 288-295. doi:10.1111/j.1471-8286.2005.01155.x

Peakall, R., \& Smouse, P. E. (2012). GenAlEx 6.5: genetic analysis in Excel. Population genetic software for teaching and research-an update. Bioinformatics, 28 (19), 2537-2539. doi:10.1093/bioinformatics/bts460

Pritchard, J. K., Stephens, M., \& Donnelly, P. (2000). Inference of population structure using multilocus genotype data. Genetics, 155 (2), 945-959.

Rabeling, C., Bollazzi, M., Bacci, M., Beasley, R. R., Lance, S. L., Jones, K. L., \& Pierce, N. E. (2013). Development and characterization of twenty-two polymorphic microsatellite markers for the leafcutter ant, Acromyrmex lundii , utilizing Illumina sequencing. Conservation Genetics Resources, 6 (2), 319-322. doi:10.1007/s12686-013-0078-3

Rabeling, C., Cover, S. P., Johnson, R. A., \& Mueller, U. G. (2007). A review of the North American species of the fungus-gardening ant genus Trachymyrmex (Hymenoptera: Formicidae). Zootaxa, 1664, 1-53.

Rabeling, C., Gonzales, O., Schultz, T., Bacci, M., Garcia, M., Verhaagh, M., . . Mueller, U. (2011). Cryptic sexual populations account for genetic diversity and ecological success in a widely distributed, asexual fungusgrowing ant.Proceedings of the National Academy of Science, USA, 108 (30), 12366-12371.

Rabeling, C., Love, C. N., Lance, S. L., Jones, K. L., Pierce, N. E., \& Bacci, M., Jr. (2014). Development of twenty-one polymorphic microsatellite markers for the fungus-growing ant, Mycocepurus goeldii (Formicidae: Attini), using Illumina paired-end genomic sequencing. Conservation Genetics Resources, 6 (3), 739-741. doi:10.1007/s12686-014-0204-x 
Richter, S. C., O’Neill, E. M., Nunziata, S. O., Rumments, A., Gustin, E. S., Young, J. E., \& Crother, B. I. (2014). Cryptic Diversity and Conservation of Gopher Frogs across the Southeastern United States. Copeia, 2014 (2), 231-237. doi:10.1643/CG-13-040

Ronque, M. U. V., Lyra, M. L., Migliorini, G. H., Bacci, M., \& Oliveira, P. S. (2020). Symbiotic bacterial communities in rainforest fungus-farming ants: evidence for species and colony specificity. Scientific Reports, 10 (1), 10172. doi:10.1038/s41598-020-66772-6

Rosenberg, N. A. (2004). distruct: a program for the graphical display of population structure. Mol Ecol Notes, 4 (1), 137-138. doi:10.1046/j.1471-8286.2003.00566.x

Rousset, F. (1997). Genetic differentiation and estimation of gene flow from F-statistics under isolation by distance. Genetics, 145 (4), 1219-1228.

Rousset, F. (2008). genepop'007: a complete re-implementation of the genepop software for Windows and Linux. Mol Ecol Resour, 8 (1), 103-106. doi:10.1111/j.1471-8286.2007.01931.x

Rozas, J., Ferrer-Mata, A., Sánchez-DelBarrio, J. C., Guirao-Rico, S., Librado, P., Ramos-Onsins, S. E., \& Sánchez-Gracia, A. (2017). DnaSP 6: DNA Sequence Polymorphism Analysis of Large Data Sets. Molecular Biology and Evolution, 34 (12), 3299-3302. doi:10.1093/molbev/msx248

Schuelke, M. (2000). An economic method for the fluorescent labeling of PCR fragments. Nat Biotechnol, 18 (2), 233-234. doi:10.1038/72708

Schultz, T. R., \& Brady, S. G. (2008). Major evolutionary transitions in ant agriculture.Proceedings of the National Academy of Science, USA, 105 (14), 5435-5440.

Schultz, T. R., Sosa-Calvo, J., Brady, S. G., Lopes, C. T., Mueller, U. G., Bacci, M., Jr., \& Vasconcelos, H. L. (2015). The most relictual fungus-farming ant species cultivates the most recently evolved and highly domesticated fungal symbiont species. American Naturalist, 185 (5), 693-703. doi:10.1086/680501

Seal, J. N. (2009). Scaling of body weight and fat content in fungus-gardening ant queens: does this explain why leaf-cutting ants found claustrally? Insectes Sociaux, 56 (2), 135-141.

Seal, J. N., \& Mueller, U. G. (2014). Instability of novel ant-fungal associations suggest that microbial interactions constrain horizontal transfer in higher fungus-gardening ants. Evolutionary Ecology, 28 (1), 157-176.

Seal, J. N., Schiøtt, M., \& Mueller, U. G. (2014). Ant-fungal species combinations engineer physiological activity of fungus gardens. Journal of Experimental Biology, 217, 2540-2547.

Seal, J. N., Thiebaud, J., \& Mueller, U. G. (2015). Gone to Texas: comparative phylogeography of two Trachymyrmex species along the southeastern coastal plain of North America. Biological Journal of the Linnean Society, 114 (3), 689-698. doi:DOI: 10.1111/bij.12426

Seal, J. N., \& Tschinkel, W. R. (2006). Colony productivity of the fungus-gardening ant,Trachymyrmex septentrionalis McCook, in a Florida pine forest (Hymenoptera: Formicidae). Annals of the Entomological Society of America, 99 (4), 673-682.

Seal, J. N., \& Tschinkel, W. R. (2007a). Co-evolution and the superorganism: switching cultivars does not alter the performance of fungus-gardening ant colonies. Functional Ecology, 21 , 988-997.

Seal, J. N., \& Tschinkel, W. R. (2007b). Energetics of newly mated queens and colony founding in the fungus-gardening ants Cyphomyrmex rimosus and Trachymyrmex septentrionalis (Hymenoptera: Formicidae). Physiological Entomology, 32, 8-15.

Seal, J. N., \& Tschinkel, W. R. (2008). Food limitation in the fungus-gardening ant, Trachymyrmex septentrionalis . Ecological Entomology, 33, 597-607. 
Seal, J. N., \& Tschinkel, W. R. (2010). Distribution of the Fungus-Gardening Ant, Trachymyrmex septentrionalis during and after a record drought. Insect Conservation and Diversity, 3 , 134-142.

Senula, S. F., Scavetta, J. T., Banta, J. A., Mueller, U. G., Seal, J. N., \& Kellner, K. (2019). Potential Distribution of Six North American Higher-Attine Fungus-Farming Ant (Hymenoptera: Formicidae) Species. Journal of Insect Science, 19 (6), 1-11. doi:10.1093/jisesa/iez118

Simon, C., Frati, F., Beckenbach, A., Crespi, B., Liu, H., \& Flook, P. (1994). Evolution, Weighting, and Phylogenetic Utility of Mitochondrial Gene Sequences and a Compilation of Conserved Polymerase Chain Reaction Primers. Annals of the Entomological Society of America, 87 (6), 651-701. doi:10.1093/aesa/87.6.651

Slatkin, M. (1987). Gene flow and the geographic structure of natural populations. Science, 236 (4803), 787-792. doi:10.1126/science. 3576198

Smith, C. C., Weber, J. N., Mikheyev, A. S., Roces, F., Bollazzi, M., Kellner, K., . . Mueller, U. G. (2019). Landscape genomics of an obligate mutualism: concordant and discordant population structures between the leafcutter-ant Atta texana and its two main fungal symbiont types. Molecular Ecology, 28 (11), 2831-2845. doi: $10.1101 / 458950$

Solomon, S. E., Bacci, M., Jr, Martins, J., Jr, Vinha, G. G., \& Mueller, U. G. (2008). Paleodistributions and Comparative Molecular Phylogeography of Leafcutter Ants (Atta spp.) Provide New Insight into the Origins of Amazonian Diversity. PLoS ONE, 3 (7), e2738.

Solomon, S. E., Rabeling, C., Sosa-Calvo, J., Lopes, C. T., Rodrigues, A., Vasconcelos, H. L., . . . Schultz, T. R. (2019). The molecular phylogenetics of Trachymyrmex Forel ants and their fungal cultivars provide insights into the origin and coevolutionary history of 'higher-attine' ant agriculture. Systematic Entomology, 44 (4), 939-956. doi:10.1111/syen.12370

Storfer, A., Murphy, M. A., Spear, S. F., Holderegger, R., \& Waits, L. P. (2010). Landscape genetics: where are we now? Mol Ecol, 19 (17), 3496-3514. doi:10.1111/j.1365-294X.2010.04691.x

Strehl, C.-P., \& Gadau, J. (2004). Cladistic analysis of paleo-island populations of the Florida harvester ant (Hymenoptera: Formicidae) based upon divergence of mitochondrial DNA sequences. Florida Entomologist, 87 (4), 576-581.

Tamura, K., Stecher, G., Peterson, D., Filipski, A., \& Kumar, S. (2013). MEGA6: Molecular Evolutionary Genetics Analysis version 6.0. Molecular Biology and Evolution, 30 (12), 2725-2729. doi:10.1093/molbev/mst197

Team, R. C. (2018). R: A language and environment for statistical computing. Vienna, Austria: R Foundation for Statistical Computing,. Retrieved from http://www.R-project.org/.

Tesson, S. V. M., Okamura, B., Dudaniec, R. Y., Vyverman, W., Londahl, J., Rushing, C., . . . Green, A. J. (2015). Integrating microorganism and macroorganism dispersal: modes, techniques and challenges with particular focus on co-dispersal.Ecoscience, 22 (2-4), 109-124. doi:10.1080/11956860.2016.1148458

Thompson, J. D., Higgins, D. G., \& Gibson, T. J. (1994). CLUSTAL W: improving the sensitivity of progressive multiple sequence alignment through sequence weighting, position-specific gap penalties and weight matrix choice. Nucleic Acids Res, 22 (22), 4673-4680. doi:10.1093/nar/22.22.4673

Toews, D., \& Brelsford, A. (2012). The biogeography of mitochondrial and nuclear discordance in animals. Molecular Ecology, 21, 3907-3930.

Trochet, A., Courtois, E. A., Stevens, V. M., Baguette, M., Chaine, A., Schmeller, D. S., \& Clobert, J. (2016). Evolution of Sex-Biased Dispersal. Q Rev Biol, 91 (3), 297-230. doi:10.1086/688097

Tschinkel, W. R., \& Seal, J. N. (2016). Bioturbation by the Fungus-Gardening Ant, Trachymyrmex septentrionalis. PLoS ONE, 11 (7), e0158920. doi:10.1371/journal.pone.0158920 


\section{AUTHOR CONTRIBUTIONS}

JNS and KK conceived the study, secured funding and permits, and collected samples. AEM conducted the molecular work and data analyses with contributions from JNS and KK. AEM and JNS led manuscript writing, and all authors edited and approved the final version. The authors declare no competing interests.

\section{DATA ACCESSIBILITY}

COI sequence data corresponding to the samples used in this study are deposited in GenBank under accession numbers MN088095-MN088120, KP282952-KP282961, and KP282964- KP283014 and can be found in Table S1. Microsatellite genotypes can be found in Table S2.

\section{TABLES}

Table 1. Details of the nine polymorphic microsatellite loci analyzed for Trachymyrmex septentrionalis ants across Florida. Superscript ${ }^{\text {a }}$ indicates deviation from Hardy-Weinberg expectations after Bonferroni corrections. Bolded and underlined p-values indicate deviation after Bonferroni correction11Note. Abbreviations include: the number of individuals genotyped $(\mathrm{N})$, number of alleles observed $(\mathrm{K})$, observed heterozygosity per locus for all regions $\left(\mathrm{H}_{\mathrm{oL}}\right)$, expected heterozygosity per locus for all regions $\left(\mathrm{H}_{\mathrm{eL}}\right)$, probability of identity per locus for all regions $\left(\mathrm{PI}_{\mathrm{L}}\right)$, observed heterozygosity per region by locus $\left(\mathrm{H}_{\mathrm{o}}\right)$, Hardy-Weinberg Equilibrium p-values per region by locus (HWE), St. George Island (SGI), ARD (Apalachicola Ranger District), and WRD (Wakulla Ranger District)

\begin{tabular}{|c|c|c|c|c|c|c|c|c|c|}
\hline & All regions & All regions & All regions & All regions & All regions & SGI & SGI & ARD & ARD \\
\hline Locus & $\mathbf{N}$ & $\mathbf{K}$ & $\mathbf{H o}_{\mathrm{L}}$ & $\mathbf{H e}_{\mathbf{L}}$ & $\mathbf{P I}_{\mathbf{L}}$ & Ho & HWE & Ho & HWE \\
\hline Ts $5^{\mathrm{a}}$ & 53 & 12 & 0.585 & 0.827 & 0.051 & 0.750 & 0.771 & 0.654 & 0.006 \\
\hline $\operatorname{Ts} 21^{\mathrm{a}}$ & 50 & 11 & 0.66 & 0.823 & 0.048 & 0.000 & 0.009 & 0.852 & 0.014 \\
\hline Ts 25 & 61 & 22 & 0.787 & 0.829 & 0.028 & 0.667 & 1 & 0.778 & 0.039 \\
\hline Ts32 & 61 & 16 & 0.754 & 0.864 & 0.031 & 0.500 & 0.428 & 0.769 & 0.199 \\
\hline Ts33 & 63 & 14 & 0.714 & 0.776 & 0.072 & 0.400 & 0.300 & 0.778 & 0.110 \\
\hline $\operatorname{Ts} 39^{\mathrm{a}}$ & 63 & 22 & 0.492 & 0.919 & 0.012 & 0.667 & 0.413 & 0.519 & 0 \\
\hline Ts41 & 60 & 17 & 0.8 & 0.843 & 0.037 & 0.500 & 0.214 & 0.792 & 0.364 \\
\hline $\operatorname{Ts} 43^{a}$ & 55 & 34 & 0.6 & 0.937 & 0.007 & 1.000 & 1 & 0.609 & 0 \\
\hline Ts46 & 59 & 22 & 0.797 & 0.921 & 0.011 & 0.500 & 0.003 & 0.833 & 0.119 \\
\hline
\end{tabular}

Table 2. Population genetic diversity indices of Trachymyrmex septentrionalis ants across Florida, as well as separated by site with major region indicated in parentheses11Note. Abbreviations include: sample size $(\mathrm{n})$, number of unique haplotypes (h), haplotype (hd) and nucleotide $(\pi)$ diversities with standard deviation (SD), and the average number of nucleotide differences $(\mathrm{k})$.

\begin{tabular}{llllll}
\hline Region & $\mathbf{n}$ & $\mathbf{h}$ & $\mathbf{h d}(\mathbf{S D})$ & $\boldsymbol{\pi}(\boldsymbol{\Sigma} \boldsymbol{\Delta})$ & $\mathbf{k}$ \\
\hline All & 87 & 38 & $0.940(0.013)$ & $0.010(0.00097)$ & 8.1 \\
Island (Panhandle) & 5 & 3 & $0.700(0.218)$ & $0.001(0.00045)$ & 1 \\
Apalachicola Ranger District (Panhandle) & 27 & 9 & $0.795(0.054)$ & $0.007(0.00093)$ & 5.3 \\
Wakulla Ranger District (Panhandle) & 30 & 19 & $0.947(0.026)$ & $0.007(0.00052)$ & 5.7 \\
North Central (Peninsula) & 11 & 7 & $0.873(0.089)$ & $0.018(0.00583)$ & 14.2 \\
Central (Peninsula) & 14 & 3 & $0.275(0.148)$ & $0.002(0.00137)$ & 1.8 \\
\hline
\end{tabular}

\section{FIGURES}

Figure 1. Localities of Trachymyrmex septentrionalisspecimen sampling sites in this study, color-coded by 
major region. The Apalachicola National Forest is highlighted in green. Major cities are denoted by gray stars and major rivers are labeled.

Figure 2. Bayesian model-based genetic clusters $(\mathrm{K}=2)$ inferred from STRUCTURE analyses using nine microsatellite loci from 64Trachymyrmex septentrionalis ants across Florida. Each vertical bar represents an individual and each section between black bars represents major regions, which are labeled above. The two colors represent the two unique genetic clusters, and the proportion of each color represents the assignment probability of that individual to each cluster.

Figure 3. Isolation by distance scatterplots showing the relationship between genetic differentiation (transformed pairwise Fst values) and geographic distance (distance between sites in km) as identified by Mantel tests for Trachymyrmex septentrionalis ants in Florida. The analyses were conducted across (A) all sampling sites across all regions, (B) all sampling sites excluding SGI, (C) all sampling sites within the ANF only, and (D) all sampling sites within the peninsula only. Regression coefficients and p-values are displayed for each analysis.

Figure 4. A TCS haplotype network for Trachymyrmex septentrionalis constructed with COI mitochondrial DNA sequences. Each circle represents a unique haplotype and the relative size of circles is proportional to the number of individuals harboring that haplotype. Colors correspond to sampling sites and align with Figure 1. Tick marks on branches indicate the number of mutations between haplotypes. Small black circles represent predicted intermediate haplotypes. Haplotype clades (Ts Clades I-III) are circled, highlighted, and labeled.

\section{Hosted file}

image1.emf available at https://authorea.com/users/350073/articles/487445-male-biaseddispersal-in-a-female-dispersed-symbiosis

\section{Hosted file}

image2.emf available at https://authorea.com/users/350073/articles/487445-male-biaseddispersal-in-a-female-dispersed-symbiosis

\section{Hosted file}

image3.emf available at https://authorea.com/users/350073/articles/487445-male-biaseddispersal-in-a-female-dispersed-symbiosis 


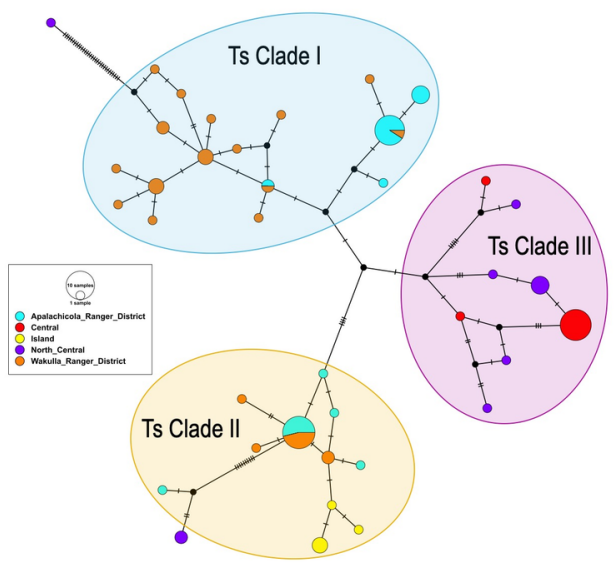

